\title{
Effect of antioxidants and mesenchymal stem cells on cisplatin induced renal fibrosis in rats
}

\begin{abstract}
Background: Mesenchymal stem cells (MSCs) have generated a great deal of excitement and promise as a potential source of all types of cells for cell-based therapeutic strategies. The reparative role of MSCs may be multifunctional and include the secretion of anti-inflammatory cytokines like TGF $\beta 1$ to limit apoptosis and dampen the inflammatory response. There are reports suggesting that antioxidants such as N N'-diphenyl-1, 4-phenylenediamine (DPPD) inhibit interstitial fibrosis induced by cisplatin. It inhibits lipid peroxidation and nephrotoxicity induced by cisplatin, where antioxidants make trapping for free radicals.
\end{abstract}

Aim: We aimed to investigate the inhibitory potential of either stem cells or DPPD on renal fibrosis in cisplatin induced tubulointerstitial fibrosis rat model.

Materials and methods: This study was carried on 40 male Sprague-Dawley rats (body weight 170-220g). Rats were divided into 4 groups as follow: Control group, received intravenous saline. Cisplatin group, received cisplatin $(6 \mathrm{mg} / \mathrm{kg}$, i.p). DPPD group, received cisplatin $(6 \mathrm{mg} / \mathrm{kg}$, i.p) at the start of experiments and three days after cisplatin administration, rats were given DPPD $(0.5 \mathrm{~g} / \mathrm{kg}$, i.p) every two days. MSCs group, received cisplatin $(6 \mathrm{mg} / \mathrm{kg}$, i.p) at the start of experiments and three days after cisplatin administration, rats were given MSCs $(1 \times 106$, i.v) single dose. 14 days after cisplatin (or saline) administration, blood samples were obtained and kidneys were removed for biochemical, histopathology and immunohistochemical markers investigations.

Results: In addition to the significant rise in urea and creatinine, cisplatin group showed atrophied glomeruli with tubular cells vacuolization and increased collagen deposition. Alpha smooth muscle actin ( $\alpha$-SMA) and fibroblast proliferation marker $\mathrm{Ki}-67$ were found to be increased in renal tissue. Lipid peroxidation and collagen formation markers showed significant elevation. Both MSCs and antioxidant ameliorated cisplatin-induced nephrotoxicity to a great extent and showed marvelous anti-fibrotic effect as evidenced by histopathological, immunohistochemical and biochemical assessments.

Conclusion: Both MSCs and antioxidant (DPPD) were found to have potent potentials to inhibit tubulointerstitial fibrosis in cisplatin induced nephrotoxicity rat model.

Keywords: antioxidants, mesenchymal, stem cells, cisplatin, kidney, rat, fibrosis
Volume I Issue 4 - 2016

\author{
Faten Zahran, ${ }^{4}$ Ahmed Nabil, ${ }^{5}$ Amro El \\ Karef, ${ }^{3}$ Ahmed Lotfy, ${ }^{2}$ Khaled Mahmoud,' \\ Walaa G Hozayen, ${ }^{5}$ Mohamed Sobh ${ }^{1,2}$ \\ 'Urology and Nephrology Center, Mansoura University, Egypt \\ 2Mansoura University, Egypt \\ ${ }^{3}$ Pathology Department, Mansoura University, Egypt \\ ${ }^{4}$ Biochemistry Department, Zagazig University, Egypt \\ ${ }^{5}$ Department of Biotechnology, Beni-Suef University, Egypt
}

Correspondence: Ahmed Nabil, Department of Biotechnology, Faculty of Postgraduate Studies for Advanced Sciences, Beni-Suef University, Beni-Suef, Egypt, Tel (+20)1000618349, Email drnabil_100@hotmail.com

Received: August 29, 2016 | Published: September 07, 2016

\section{Background}

Inflammation of the tubulointerstitial compartment, leading to fibrosis, is a major factor in the progressive loss of renal function. About $80 \%$ of total kidney volume is composed of tubular epithelial cells and cells within the interstitial space. There are also a small number of resident mononuclear cells and fibroblasts. It is widely recognized that progressive renal disease is accompanied by tubulointerstitial changes characterized by tubular atrophy, increased number of interstitial fibroblasts, phenotypic change of interstitial cells, accumulation of matrix proteins, and interstitial infiltrate of mononuclear cells.

Deterioration of renal function is determined to a large extent by the degree of tubulointerstitial changes. However, the pathogenic mechanisms of tubulointerstitial changes have not yet been elucidated fully. Evidence from many studies suggests that common pathogenic mechanisms exist in the pathogenesis of tubulointerstitial changes. However, there is little detailed description of the molecular mechanism of renal fibrosis, and moreover, an effective treatment procedure has not been established. ${ }^{1}$

Cis-Diamminedichloroplatinum (II) (cisplatin) is an effective antitumor agent for testis, bladder, lung, and ovarian cancers. Its clinical use is limited due to the induction of tubular necrosis and acute kidney injury. ${ }^{2-4}$ In experimental animals, it causes renal interstitial fibrosis on the long term. ${ }^{5}$

The development of interstitial fibrosis is thought to cause irreversible renal dysfunction. ${ }^{6}$ Cisplatin increases the lipid peroxidation level in rat renal slices and the synthesis of hydrogen peroxide in cultured renal cells. ${ }^{6}$ These findings suggest that reactive oxygen species (ROS) have an important role in the pathogenesis of cisplatin-related fibrosis. ${ }^{7}$ Cisplatin induces cellular infiltration of macrophages and fibroblasts from the blood stream to the tubulointerstitium, where macrophages starts to secretes growth factors and cytokines that causes disequilibrium between apoptosis and proliferation of tubular cells leading to tubular atrophy. ${ }^{8}$ Also 
fibroblasts are activated into myofibroblasts that secrets collagen leading to further fibrosis. ${ }^{9}$

There are reports that antioxidants such as N N'-diphenyl-1, 4-phenylenediamine (DPPD) inhibit interstitial fibrosis induced by cisplatin. ${ }^{10,11}$ It prevents the increases in content of lipid peroxides and nephrotoxicity induced by cisplatin, where antioxidants are able to make trapping for free radicals.. ${ }^{12}$

Also some of the most promising and frequent research in the field of regenerative medicine has focused on the use of stem cells. These cells, by definition, are undifferentiated cells with significant selfrenewal capabilities. Additionally, stem cells are able to proliferate and establish daughter cell lines for tissue generation. ${ }^{13}$ The bone marrow is the source of mesenchymal SC (MSCs) from which many tissues may be obtained. The ability of adult MSCs to "transdifferentiate" could revolutionize regenerative medicine. ${ }^{14}$

MSCs are of great interest to both clinicians and researchers for their great potential to enhance tissue engineering. Their ease of isolation, manipulability and potential for differentiation are specifically what has made them so attractive. ${ }^{14}$ MSCs can repair the injured kidney through variable mechanisms where stem cells are able to make Homing to the injured kidney and secretion of antiinflammatory cytokines like dampen the inflammatory response also it differentiate into tubular epithelial cells. ${ }^{15}$

\section{Aim of the work}

This study aimed to study the effect of DPPD and mesenchymal stem cells on amelioration of renal fibrosis that induced by cisplatin in rats.

\section{Materials and methods}

The study was carried on 40 male Sprague-Dawley rats (body weight $170-220 \mathrm{~g}$ ). Rats were bred and maintained in an airconditioned animal house with specific pathogen free conditions, and were subjected to a 12:12-h daylight/darkness and allowed unlimited access to chow and water. All the ethical protocols for animal treatment were followed and supervised by the animal facilities, Medical Experimental Research Centre, Faculty of Medicine, Mansoura University. They were divided into 4 groups as follow:

a. Saline group, where 10 rats received intravenous saline instead of cisplatin and served as the control.

b. Cisplatin group, where 10 rats received cisplatin $(6 \mathrm{mg} / \mathrm{kg}$, intraperitoneal) at the start of experiments.

c. Cisplatin+DPPD group, where 10 rats received cisplatin $(6 \mathrm{mg} /$ $\mathrm{kg}$, intraperitoneal) at the start of experiments and three days after cisplatin administration, rats were given DPPD $(0.5 \mathrm{~g} / \mathrm{kg}$, intraperitoneal) every two days

d. Cisplatin+MSCs group, where 10 rats received cisplatin $(6 \mathrm{mg}$ / $\mathrm{kg}$, intraperitoneal) at the start of experiments and three days after cisplatin administration, rats were given MSCs $(1 \times 106$, intravenous) single dose.

At day14 after cisplatin or saline administration, blood samples were obtained and kidneys were removed. ${ }^{16}$

\section{Mesenchymal stem cell dose injection}

Mesenchymal stem cells were injected in rats through caudal veins
$1 \times 106$ for each rat according to the protocol. Rats were killed under pentobarbital anesthesia 14 days after MSCs treatment.

\section{Protocol of MSCs isolation}

In this study we obtained cells from bone marrow of SpragueDawley rats.

Preparation of complete media: We used Dulbecco's modified Eagles medium (DMEM) media so we aliquoting it under laminar air flow at $50 \mathrm{ml}$ tube each contain $45 \mathrm{ml}$ and preserve it at $(2-8)^{\circ} \mathrm{C}$. Fetal bovine serum was preserved at $(-20)^{\circ} \mathrm{C}$, then it was put in water bath at $37^{\circ} \mathrm{C}$ until it was become liquid then it was deactivated at $56^{\circ} \mathrm{C}$ for $30 \mathrm{~min}$ then it was aliquoted at $15 \mathrm{ml}$ tube each contain (10-15) $\mathrm{ml}$. Anti-biotic preserved at $(-20)^{\circ} \mathrm{C}$ so we put it at water bath for $20 \mathrm{~min}$ then aliquoting at $15 \mathrm{ml}$ tube each contain (10-15)ml. At the $50 \mathrm{ml}$ tubes which contain $45 \mathrm{ml}$ DMEM we added $5 \mathrm{ml} \mathrm{FBS}$ and $0.5 \mathrm{ml}$ anti biotic.

Methods of obtaining BM specimens for isolation and culture of BM-MSCs: The animals were killed by cervical dislocation, and then the skin was sterilized with $70 \%$ ethyl alcohol before cutting the skin. The femurs and tibia were carefully dissected from adherent soft tissues. Then they were placed into sterilized beaker containing $70 \%$ ethyl alcohol for 1-2min. The bones were put in Petri dish contain PBS for wash. The bones were taken to laminar air flow to extract the $\mathrm{BM}$. The two ends of the bones were removed using sterile scissors. Bones were flushed with $3-5 \mathrm{ml}$ of complete media at one end, the marrow plugs were expelled from the opposite end of bone into sterile $15 \mathrm{ml}$ tube. The marrow plugs were cultured in $20 \mathrm{ml}$ complete media.

Culturing of bone marrow: The cells were cultured in $75 \mathrm{~cm}^{2}$ tissue culture flask containing $10-15 \mathrm{ml}$ complete media in humidified incubator at $37^{\circ} \mathrm{C}$ in $5 \% \mathrm{CO}_{2}$ and $95 \%$ air (by volume). The cultured cells were examined daily using the inverted microscope to follow up the growth of the cells. After $24 \mathrm{~h}$ the old media were removed by aspiration using sterile pipette. The cells were then washed with $5 \mathrm{ml}$ PBS. Then $15 \mathrm{ml}$ complete media was added to the flask. MSCs were distinguished from other bone marrow cells by their ability to adhere to tissue culture polystyrene flask. The second exchange for media was done after 3-4 days. The media changed twice a week. The cells take 4 weeks to be confluent and be ready for Passaging.

Passage 1: Adherent cells attach themselves to surface of tissue culture polystyrene flasks or dishes using proteins secreted by the cells. To dislodge cells from the flask, the protein bridge must be broken. Trypsin is proteolytic (protein degrading) enzyme that will break proteins at specific places. EDTA is often found in Trypsin solutions. EDTA allows Trypsin to work more efficiently by engaging certain metal ions that may inhibit its activity.

The flask was examined under the inverted microscope to check the cell density and contamination. The old media was removed; the culture cells were washed with PBS. The PBS was left on the cells for at least 30 second to remove as much extracellular proteins as possible. The PBS was removed and 1-2ml of Trypsin/EDTA solution which has been prewarmed at room temp.

The flasks of cultured cells were sited inside the incubator for about for about $2 \mathrm{~min}$. Then the flasks were checked under inverted microscope to make sure that adherent cells were lifted off the flask. The detached cells appeared rounded. All remaining attached cells were excluded. $5 \mathrm{ml}$ of complete media was added to stop trypsinization, and then test the cell viability. Two new tissue culture 
flasks were prepared containing $15 \mathrm{ml}$ complete media. The $5 \mathrm{ml}$ in the old flask separated into the two flasks, and then incubated in humidified incubator at $37^{\circ} \mathrm{C}$ in $5 \% \mathrm{CO}_{2}$ and $95 \%$ air.

Passage 2: Under the laminar airflow $14 \mathrm{ml}$ StemXvivo media was removed to gelatinized $75 \mathrm{~cm}^{2}$ polypropylene flask. The $2 \mathrm{ml}$ detached cells StemXvivo media suspension was transferred to the flask. The flask was incubated in $5 \% \mathrm{CO}_{2}$ and $37^{\circ} \mathrm{C}$ incubator. After 3-4 days, the old media was removed containing the non-adherent cells. $5 \mathrm{ml}$ PBS $1 \mathrm{x}$ was pipette in the flask for wash then aspirated out of the flask. New 16 StemXvivo media $16 \mathrm{ml}$ StemXvivo media was added.

The process of feeding was repeated till adherent cells reach $80-90 \%$ confluence. On reaching $80-90 \%$ confluence, $4 \mathrm{ml}$ from the detaching solution was added (Collagenase 1a: $0.02 \%$ EDTA $+0.5 \%$ BSA in PBS) (1:1) to detach the adherent cells. The flask was incubated at $\mathrm{CO}_{2}$ incubator $37^{\circ} \mathrm{C}$ and $5 \% \mathrm{CO}_{2}$ for 4 minutes. After incubation, percussion on the bottom of the flask was done to detach the adherent cells.

Cell detachment was inspected under the inverted microscope. The detached cells were removed within the detaching solution out of the flask and pipette into sterile $50 \mathrm{ml}$ tube. $3 \mathrm{ml}$ DMEM media was added to the flask to collect more detached cells. The detached cells within the DMEM were removed from the flask and pipette into the sterile $50 \mathrm{ml}$ tube. Centrifugation at $300 \mathrm{xg}$ for $10 \mathrm{~min}$ to get the cell pellet. Then supernatant was removed and the pellet was suspended in StemXvivo Media. The volume of StemXvivo Media was estimated according to the number of flasks needed for passage $2(1 \mathrm{ml}$ for every $25 \mathrm{cmm}^{2}$ and $2 \mathrm{ml}$ for every $75 \mathrm{cmm}^{2}$ ). More passages were performed till the suitable number of cells was obtained.

Counting MSCs: Stem cells were suspended in $1 \mathrm{ml}$ of appropriate media. From this cell suspension, $10 \mu 1$ was removed for counting. Depending on the estimated cell number, a dilution factor between two and ten was used to count cells. Test the cell viability $10 \mu 1$ of cells was add to $10 \mu 1$ of Trypan blue $0.4 \%$ (Lonza, USA) and mixed them well and take $10 \mu 1$ of the mixture and put it on hemocytometer (Neubauer, Germany) and count cell under Ordinary microscope (Olympus CX31, USA).

Investigations provided to measure renal injury: Rats were sacrificed to evaluate the severity of injury in each kidney. At the end point all rats were sacrificed under anesthesia induced with phenobarbital sodium injection $(50 \mathrm{mg} / \mathrm{kg}$ body weight, intraperitoneal). Kidneys were removed, cut transversely into 3 slices. One part was embed in Tissue Tek (OCT compound) for immunofluorescent study, the second part was snap-frozen in liquid nitrogen for future genetic study and the last slice was fixed in $10 \%$ buffered formalin, and embedded in paraffin for morphological studies. ${ }^{17}$

Biochemical examination of blood and tissue: Blood samples were used for determination of serum creatinine and BUN. Tissue samples were used for determination of malondialdehyde (MDA) and hydroxyproline. These parameters were measured using an automated spectrophotometer (Slim Plus, Italy) and microplate Reader (Stat Fax 3200, Awareness).

Analysis of kidney histopathology: Serial $4-\mu \mathrm{m}$ sections of the cortex and the medulla of the kidney was stained with hematoxylin and eosin (H\&E) and Masson trichrome for pathological examination.

\section{Immunohistochemical studies}

Indirect immunofluorescence was performed to detect collagen as a marker for tubulointerstitial injury. Also staining with $\alpha$-SMA and Ki-67 immunohistochemistry markers to show the regeneration in renal tubulointerstitium and fibrosis was carried out.

\section{Analysis of tubulointerstitial fibrosis}

Total renal collagen was measured biochemically. In brief, an accurately weighed portion of the kidney was homogenized in distilled water, hydrolyzed in $10 \mathrm{~N} \mathrm{HCl}$, and incubated at $110^{\circ} \mathrm{C}$ for $18 \mathrm{~h}$. The hydrolysate was dried by speed-vacuum centrifugation and redissolved in buffer $(25 \mathrm{~g}$ of citric acid, $6 \mathrm{ml}$ of glacial acetic acid, $60 \mathrm{~g}$ of sodium acetate, and $17 \mathrm{~g}$ of sodium hydroxide in $500 \mathrm{ml} .^{18}$ Total hydroxyproline in the hydrolysate was determined according to the chemical method of Kivirikko et al. ${ }^{19}$ Total collagen in the tissue was calculated on the assumption that collagen contains $12.7 \%$ hydroxyproline by weight. Final results were expressed as $\mu \mathrm{g} / \mathrm{mg}$ kidney wet weight. ${ }^{19}$

\section{Quantitative determination of MDA in tissue extract}

MDA is the end product of fatty acid peroxidation reacts with thiobarbaturic acid in acidic medium at temperature of 95 Celsius and form a colored complex. ${ }^{20}$

\section{Histopathological examination}

Kidneys were perfused in a retrograde fashion through the abdominal aorta using saline $0.9 \%$ till complete clearance of the perfusion fluid, and then $10 \%$ neutral buffered formalin for in situ fixation. Both kidneys in all groups were harvested, cut longitudinally, and send for pathological evaluation in 10\% neutral buffered formalin. Samples were processed and embedded in paraffin wax and sections ( $4 \mu \mathrm{m}$ thick) were evaluated for the following:

Tubular injury score: Sections were stained with H \& E for light microscopic examination. In the cisplatin-induced ARF model, tubular injury is most evident in the outer stripe of the outer medulla (OSOM). Thus, the degree of proximal tubular injury in this area was assessed and quantified in accordance with the scoring system modified by Kinomura et al. ${ }^{21}$ Twenty randomly selected fields were observed at a magnification of $x 400$. The degree of tubular injury was quantified as a score between 0 and 5 as the following: 0: normal; 1: tubular cells exhibiting desquamation from the tubular basement membrane (TBM), swelling, vacuolar degeneration and necrosis involving $<20 \%$ of the tubules; $2: 20-40 \%$ tubules are involved; 3 : 40-60\%; 4: 60-80\%; and 5: 80-100\%.

Detection of interstitial fibrosis: Renal tissue samples of the experiment were stained with Masson trichrome. This stain is used as routine connective tissue stain. It stains collagen blue while nuclei are stained red to blue. ${ }^{22}$ To quantify interstitial fibrosis, the fibrotic area was measured by a color image analyzer (Image J 1.32) in five randomly selected fields in the OSOM and cortico-medullary junction. The blood vessels were avoided. The percentage of fibrotic area per unit area was calculated as per Yamate et al. ${ }^{23} 1995$ calculations..$^{23}$

\section{Immunohistochemical staining for $\alpha$-SMA and Ki-67}

Detection of $\alpha$-SMA: The degree of $\alpha$-SMA in all groups was assessed in renal tissue samples using a specific kit that detect $\alpha$-SMA 
protein in rat cells (Dakocytomation, Glostrup, Denmark). The myofibroblast, a specialized fibroblast characterized by cytoplasmic stress fibers with $\alpha$-SMA. The $\alpha$-SMA is commonly used as a marker of myofibroblast formation. Antibodies against the $\alpha$-SMA antigen have proven valuable. Quantification of $\alpha$-SMA antigen is an indicator of myofibroblast and allows direct monitoring of myofibroblast in a specified tissue. ${ }^{24}$ The $\alpha$-SMA in OSOM was counted in 20 randomly selected fields at 400x magnification in each kidney section. ${ }^{21}$

Detection of Ki-67 antigen: Ki-67 is a proliferation marker for well-developed myofibrblast which responsible for collagen secretion that cause fibrosis and detected in tissue samples using a specific kit that detect Ki-67 antigen in rat cells (Dakocytomation, Glostrup, Denmark). ${ }^{25}$ The Ki-67 antigen is a large nuclear protein preferentially expressed during all active phases of the cell cycle (G1, S, G2 and $\mathrm{M}$ phases), but absent in resting (G0) cells. Antibodies against the $\mathrm{Ki}-67$ antigen have proven valuable. The number of Ki-67-positive nuclei in the OSOM was counted in 20 randomly selected fields at 400x magnification in each kidney section. ${ }^{21}$

\section{Statistical analysis}

Data were tabulated, coded then analyzed using the computer program SPSS (Statistical package for social science) version 17.0 to obtain descriptive data. Descriptive statistics were calculated in the form of mean \pm standard deviation (SD) and median, minimum and maximum. In the statistical comparison between the different groups, the significance of difference was tested using one of the following tests: ANOVA (analysis of variance): Used to compare between more than two groups of numerical (parametric) data followed by post-hoc tukey, Kruskal Wallis test: Used to compare between more than two groups of numerical (non-parametric) data followed by mann-whitney for pairwise comparisons or Repeated measures ANOVA (analysis of variance): Used to compare between more than two related groups of numerical (parametric) data followed by post-hoc LSD. A P value $<0.05$ was considered statistically significant.

\section{Results}

The present study involved 4 groups and the results of studied parameters of these groups were analysed. At 14 days after cisplatin (or saline) administration, blood samples were obtained and kidneys were removed for biochemical, histopathology and immunohistopathological markers investigations.

\section{Renal function monitoring}

Serum creatinine and BUN in all studied groups: Renal function was monitored via assay of both serum creatinine and BUN. At day Table 1 shows that the control group had no significant change in serum creatinine and BUN. Meanwhile, only positive and antioxidant groups showed significant increase in serum creatinine and BUN compered to control group $(\mathrm{p}<0.001)$ but stem cells group showed no significant change compared to control group. While, antioxidant group showed significant decrease in serum creatinine and BUN compared to positive group $(\mathrm{p}<0.05)$ but stem cells group showed significant decrease compared to positive group $(\mathrm{p}<0.001)$ and significant decrease compared to antioxidant group $(\mathrm{p}<0.05)$.

Table I Effect of antioxidant and mesenchymal stem cell therapy on serum creatinine and BUN in rat fibrosis model induced by cisplatin

\begin{tabular}{|c|c|c|c|c|c|c|}
\hline Cr. (mg/dl) & & Control group & Positive group & Antioxidant group & Stem cells group & \\
\hline \multirow[t]{6}{*}{ I4 DAYS } & Mean & 0.49 & 1.08 & 0.85 & 0.66 & \multirow{6}{*}{$<0.00 I^{* *}$} \\
\hline & & & & & & \\
\hline & $\pm \mathrm{SD}$ & 0.03 & 0.2 & 0.13 & 0.18 & \\
\hline & $\mathrm{PI}$ & & $<0.001^{* *}$ & $<0.001 * *$ & 0.06 & \\
\hline & P2 & & & $0.008^{*}$ & $<0.001^{* *}$ & \\
\hline & P3 & & & & $0.04 *$ & \\
\hline \multicolumn{7}{|c|}{ BUN (mg/dl) } \\
\hline \multirow[t]{6}{*}{ I4 DAYS } & Mean & 19.18 & 54.1 & 34.16 & 26.45 & \multirow{6}{*}{$<0.00 I^{* *}$} \\
\hline & & & & & & \\
\hline & $\pm \mathrm{SD}$ & 1.49 & 6.56 & 6.37 & 6.04 & \\
\hline & $\mathrm{PI}$ & & $<0.001^{* *}$ & $<0.001 * *$ & $0.028 *$ & \\
\hline & P2 & & & $<0.001 * *$ & $<0.001^{* *}$ & \\
\hline & P3 & & & & $0.018^{*}$ & \\
\hline
\end{tabular}

\footnotetext{
P: Probability *: significance $\leq 0.05 * *$ : high significance

Test used: One way ANOVA followed by post-hoc tukey for multiple comparisons

$\mathrm{PI}$ : significance relative to control group

P2: significance relative to positive group

P3: significance relative to Antioxidant group
} 


\section{Collagen formation and fibrosis markers assay}

Hydroxyproline content in kidney tissue samples in all studied groups: Collagen formation and fibrosis were assessed via assay of hydroxproline content in renal tissue. At day 14, hydroxyproline content was found to be significantly increased in all studied groups compared to control group ( $\mathrm{p} \leq 0.001)$. Meanwhile it was significantly decreased in antioxidant and stem cells groups compared to positive group ( $\mathrm{p} \leq 0.001)$. Also, stem cells group showed significant decrease in hydroxyproline content compared to antioxidant group $(\mathrm{p} \leq 0.001)$ (Table 2).

\section{Lipid Peroxidation assay}

Malondialdehyde in tissue extract in all studied groups: In our study lipid peroxidation was monitored via assay of MDA content in renal tissue. According to (Table 3), MDA content at day 14 was significantly increased in positive compared to control group $(\mathrm{p} \leq 0.001)$. Significant increase in antioxidant group compared to control group $(\mathrm{p} \leq 0.05)$ was found. But compared to control group, stem cells group showed no significant change in MDA content. Moreover, antioxidant and stem cells groups showed significant decrease in MDA content compared to positive group $(\mathrm{p} \leq 0.001)$ with no significance found be- tween stem cell group and antioxidant group.

\section{Histopathological examination}

Tubular injury score and fibrosis score: At day 14 kidneys were nephrectomised and were evaluated for tubular injury and fibrosis score (Figure 1). Both tubular injury and fibrosis scores were increased significantly in the three groups compared to control group. Meanwhile they were significantly lower in stem cells group and antioxidant group compared to positive group $(\mathrm{p}<0.05)$. It should be noted that stem cells group showed no significant change compared to antioxidant group (Table 4).

\section{Immunohistochemical staining}

Both $\alpha$-SMA as a marker of myelofibrosis and Ki-67 as a marker for cell proliferation were assayed: At day 14 , both $\alpha$-SMA-positive cells and $\mathrm{Ki}-67$ positive cells were significantly increased in all studied groups compared to control group $(\mathrm{p} \leq 0.001)$ but they showed significant decrease in antioxidant and stem cells groups compared to positive group $(\mathrm{p} \leq 0.001)$. Also, stem cells group showed significant decrease in $\alpha$-SMA-positive cells compared to antioxidant group $(p \leq 0.001)$ meanwhile it showed no significant change in Ki-67 proliferation marker compared to antioxidant group (Table 5 \& Figure 2).

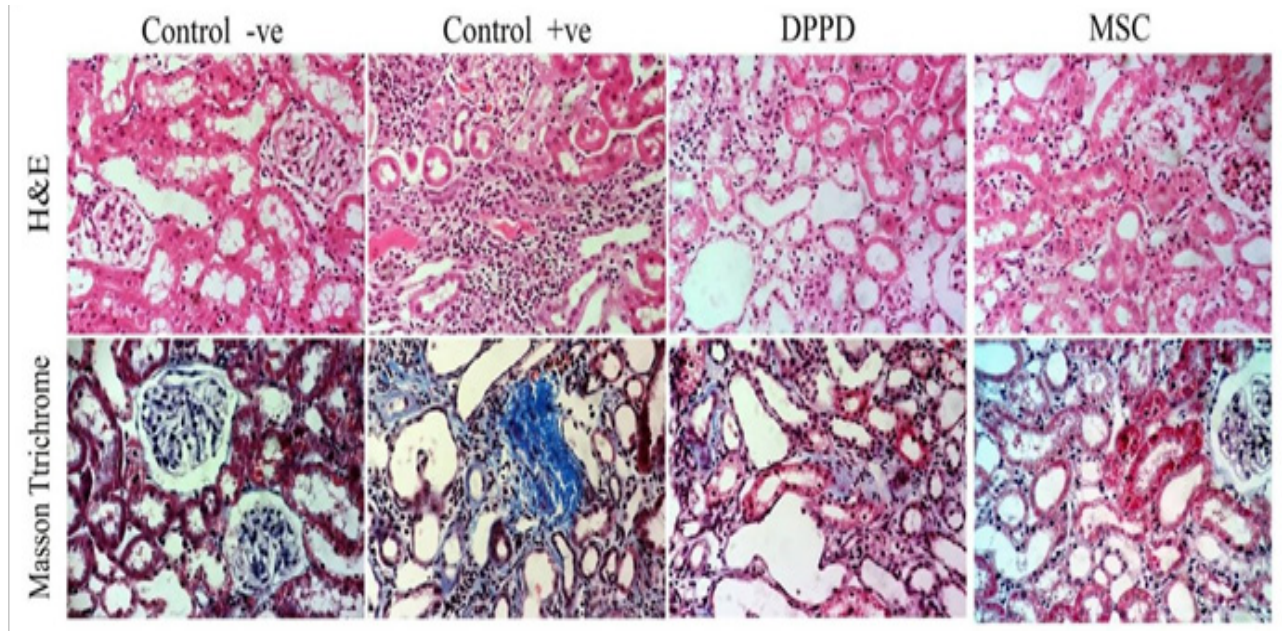

Figure I Effect of antioxidant and mesenchymal stem cell therapy on tubular injury and fibrosis score in rat fibrosis model induced by cisplatin.

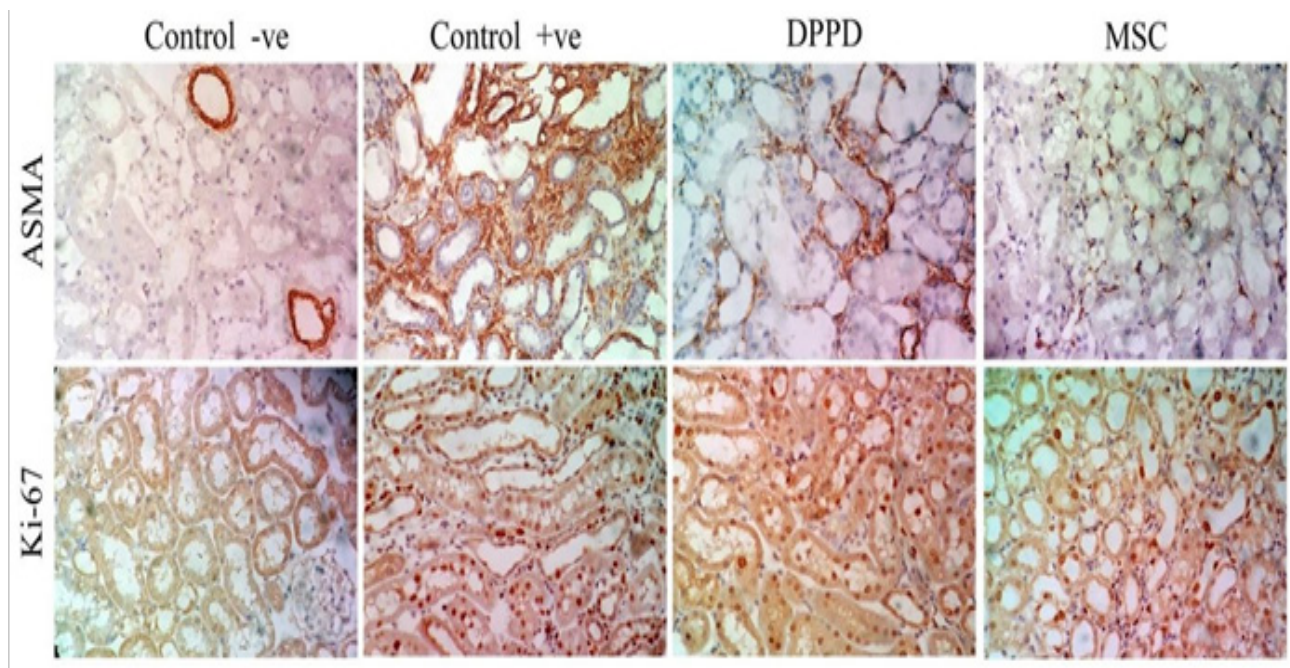

Figure 2 Immunohistochemical staining for $\alpha$-SMA and Ki-67 proliferation marker. 
Table 2 Effect of antioxidant and mesenchymal stem cell therapy on Hydroxyproline in rat fibrosis model induced by cisplatin

\begin{tabular}{|c|c|c|c|c|c|c|}
\hline \multirow{2}{*}{\multicolumn{2}{|c|}{$\begin{array}{l}\text { Hydroxyproline (ug/mg kidney } \\
\text { tissue) }\end{array}$}} & \multicolumn{4}{|l|}{ Groups } & \multirow{2}{*}{$\mathbf{P}$} \\
\hline & & Control group & Positive group & Antioxidant group & Stem cells group & \\
\hline \multirow{3}{*}{ I4 DAYs } & Mean & 21.44 & 71.92 & 37.72 & 30.06 & \multirow[t]{3}{*}{$<0.001 * *$} \\
\hline & $\pm \mathrm{SD}$ & 0.48 & 2.89 & 2.36 & 1.44 & \\
\hline & $\mathrm{PI}$ & & $<0.001 * *$ & $<0.001 * *$ & $<0.001 * *$ & \\
\hline
\end{tabular}

P: Probability *: significance $\leq 0.05 * *$ : high significance

Test used: One way ANOVA followed by post-hoc tukey for multiple comparisons

$\mathrm{PI}$ : significance relative to control group

P2: significance relative to positive group

P3: significance relative to Antioxidant group

Table 3 Effect of antioxidant and mesenchymal stem cell therapy on MDA in tissue extract in rat fibrosis model induced by cisplatin

\begin{tabular}{|c|c|c|c|c|c|c|}
\hline \multirow{2}{*}{\multicolumn{2}{|c|}{ MDA (nmol /g tissue) }} & \multicolumn{4}{|l|}{ Groups } & \multirow{2}{*}{$\mathbf{P}$} \\
\hline & & Control group & Positive group & Antioxidant group & Stem cells group & \\
\hline \multirow{5}{*}{ I4 DAYS } & Mean & 21.94 & 36.58 & 26.7 & 24.22 & \multirow[t]{5}{*}{$<0.00 I^{* *}$} \\
\hline & $\pm \mathrm{SD}$ & 1.56 & 2.98 & 1.83 & 3.3 & \\
\hline & $\mathrm{PI}$ & & $<0.001 * *$ & $0.00 I^{*}$ & 0.2 & \\
\hline & $\mathrm{P} 2$ & & & \multirow[t]{2}{*}{$<0.001 * *$} & $<0.001 * *$ & \\
\hline & P3 & & & & 0.14 & \\
\hline
\end{tabular}

P: Probability *: significance $\leq 0.05 * *$ : high significance

Test used: One way ANOVA followed by post-hoc tukey for multiple comparisons

$\mathrm{PI}$ : significance relative to control group

$\mathrm{P} 2$ : significance relative to positive group

P3: significance relative to Antioxidant group

Table 4 Effect of antioxidant and mesenchymal stem cell therapy on tubular injury and fibrosis score in rat fibrosis model induced by cisplatin

\begin{tabular}{|c|c|c|c|c|c|c|}
\hline \multirow{2}{*}{ Tubular Injury } & & \multicolumn{4}{|l|}{ Groups } & \multirow{2}{*}{$\mathbf{P}$} \\
\hline & & Control group & Positive group & Antioxidant group & Stem cells group & \\
\hline \multirow{5}{*}{ I4 DAYS } & Median & 0 & 4 & 2 & 2 & \multirow[t]{5}{*}{$<0.00 I^{* *}$} \\
\hline & Minimum & 0 & 2 & I & I & \\
\hline & Maximum & 0 & 5 & 3 & 3 & \\
\hline & $\mathrm{P} 2$ & & & $0.01 *$ & $0.004 *$ & \\
\hline & P3 & & & & 0.68 & \\
\hline \multicolumn{7}{|l|}{ fibrosis score } \\
\hline \multirow{6}{*}{ I4 DAYS } & Median & 1.09 & 3.78 & 2.13 & 1.66 & \multirow[t]{6}{*}{$<0.00 I^{* *}$} \\
\hline & Minimum & 0.95 & 2.36 & 1.35 & 1.12 & \\
\hline & Maximum & 1.35 & 5.03 & 2.6 & 2.21 & \\
\hline & $\mathrm{PI}$ & & $<0.001 * *$ & $0.001 *$ & $0.025 *$ & \\
\hline & $\mathrm{P} 2$ & & & $0.02 *$ & $0.001 *$ & \\
\hline & P3 & & & & 0.28 & \\
\hline
\end{tabular}

P: Probability *: significance $\leq 0.05 * *$ : high significance

Test used: Kruskal wallis test followed by mann-whitney for multiple comparisons

$\mathrm{PI}$ : significance relative to control group

P2: significance relative to positive group

P3: significance relative to Antioxidant group

Citation: Zahran F, Nabil A, Karef AEl, et al. Effect of antioxidants and mesenchymal stem cells on cisplatin induced renal fibrosis in rats.J Stem Cell Res Ther. 2016; I(4):I50-I58. DOI: I0.I5406/jsrt.2016.01.00026 
Table 5 Effect of antioxidant and mesenchymal stem cell therapy on $\alpha$-SMA-positive and Ki-67 positive cells/HPF in rat fibrosis model induced by cisplatin

\begin{tabular}{|c|c|c|c|c|c|c|}
\hline \multirow{2}{*}{$\alpha$-SMA-positive cells/HPF } & \multicolumn{5}{|c|}{ Groups } & \multirow{2}{*}{$\mathbf{P}$} \\
\hline & \multicolumn{2}{|c|}{ Control group } & Positive group & Antioxidant group & Stem cells group & \\
\hline \multirow{5}{*}{ I 4 DAYS } & Mean & 9.4 & 298.2 & 81.4 & 54.6 & \multirow[t]{5}{*}{$<0.001 * *$} \\
\hline & $\pm \mathrm{SD}$ & 1.07 & 13.78 & 11.97 & 8.24 & \\
\hline & $\mathrm{PI}$ & & $<0.001 * *$ & $<0.001 * *$ & $<0.001 * *$ & \\
\hline & $\mathrm{P} 2$ & & & $<0.001 * *$ & $<0.001 * *$ & \\
\hline & P3 & & & & $<0.001 * *$ & \\
\hline \multicolumn{7}{|l|}{ Ki-67 positive cells/HPF } \\
\hline \multirow{5}{*}{ I4 DAYS } & Mean & 7.9 & 83.9 & 55 & 53.8 & \multirow[t]{5}{*}{$<0.001 * *$} \\
\hline & $\pm \mathrm{SD}$ & 2.02 & 16.08 & 6.22 & 5.45 & \\
\hline & $\mathrm{PI}$ & & $<0.001 * *$ & $<0.001 * *$ & $<0.001 * *$ & \\
\hline & $\mathrm{P} 2$ & & & $<0.001 * *$ & $<0.001 * *$ & \\
\hline & P3 & & & & 0.99 & \\
\hline
\end{tabular}

P: Probability *: significance $\leq 0.05 * *$ : high significance

Test used: One way ANOVA followed by post-hoc tukey for multiple comparisons

$\mathrm{PI}$ :significance relative to control group

P2: significance relative to positive group

P3: significance relative to Antioxidant group

\section{Discussion}

Although the clinical management of AKI patients has significantly improved in recent years, we still lack specific therapies to enhance kidney repair. Recovery after acute injury is critical for patient morbidity and mortality in the hospital setting. ${ }^{26}$

Cisplatin is a potent antineoplastic drug used in the treatment of solid tumors. Clinicians should pay attention to its expected nephrotoxic effects. Many theories were reported about cisplatininduced nephrotoxicity. These mechanisms included its role in induction of lipid peroxidation, mitochondrial dysfunction, injury of DNA, and structural protein degradation. ${ }^{27-29}$ Despite of that, the real mechanism is not well known so far. The platinum components of cisplatin bind to the DNA and this process leads to DNA damage and as a consequence of this reaction free radicals and reactive oxygen species will be elevated. ${ }^{30}$

Tubulointerstetial fibrosis is a directly related to cisplatin administration via the increased expression of reactive oxygen specie's and the increased free radicals especially raised malondialdehyde levels as was previously reported. ${ }^{16,31,32}$

In this study we used cisplatin for induction of acute kidney injury in experimental rat model. Where we tried to study the potential impact mesenchymal stem cells and N N'-diphenyl-1, 4-phenylenediamine as member of the antioxidant agents in ameliorating the interstitial fibrosis induced via cisplatin. We thoroughly assessed the collagen formation and tubulointerstitial fibrosis on the histopathological, immunohistochemical staining and biochemical levels.

Our current study showed that the administration of either mesenchymal stem cells or the antioxidant (DPPD) offered significant amelioration of the nephrotoxicity and fibrosis induced by cisplatin. Where serum creatinine and BUN showed significant decrease in the stem cells and antioxidant groups in comparison to the cisplatin group as was also reported previously by other studies. ${ }^{33,16}$

Tubular injury and interstitial fibrosis are cardinal features of cisplatin induced nephrotoxicity on histopathological evaluation. ${ }^{34}$ Both of them had been carefully assessed and scored in our study. In line with some other reports. ${ }^{35,16}$ significant reduction has been found in both stem cell and antioxidant groups than in the cisplatin group and this was further proved and fortified via immunohistochemical assay of $\alpha$-SMA and Ki-67 in renal tissue. Both $\alpha$-SMA and Ki-67 contents were significantly lower in renal tissue denoting decreased myelofibrosis, collagen formation and cell proliferation in the stem cell group and antioxidant group more than cisplatin group.

Lipid peroxidation has been linked with cisplatin induced tubulointerstitial fibrosis as it has been suggested that binding of cisplatin to the renal base transport system and the following peroxidation of membrane lipids may account for its renal toxicity. ${ }^{36}$ In the present study, treatment with stem cells or antioxidant inhibited the increase in lipid peroxidation induced by cisplatin in renal tissue which was measured in terms of MDA, a stable metabolite of the free radical mediated lipid peroxidation cascade. MDA level was increased significantly in cisplatin treated group. Either stem cells or antioxidant has reversed the increased level of level to a considerable extent, thereby confirming their inhibition of lipid peroxidation in cisplatin induced acute kidney injury. The ability of either stem cells or antioxidant in inhibition of lipid peroxidation and their potent role as free radical scavengers was stated before in other reports. ${ }^{35,38}$

Also collagen synthesis and consequently fibrosis was much significantly suppressed as per hydroxylproline content assay in the renal tissue of the antioxidant and stem cell groups. Owing to the reports by Ognjanovic et al..$^{37}$ and Ohnishi et al. ${ }^{38}$ they addressed the same findings as in our study. ${ }^{36,37,39}$ 
It is worthy to mention that in our study despite both MSCs and antioxidant (DPPD) proved to inhibit collagen formation and to have an anti-fibrotic effect but MSCs has been found to more potent.

\section{Conclusion}

We concluded that both mesenchymal stem cells and antioxidants had the ability to significantly ameliorate the collagen formation and interstitial fibrosis induced by cisplatin. May be more studies are still needed to solidify our findings and to study the other possible mechanisms underlying their anti-fibrotic potentials to get them from bench to bedside.

\section{Acknowledgements}

The authors would extend their thanks to the whole technicians in the Medical Experimental Research Centre, Faculty of Medicine, Mansoura University for their great dedicated work.

\section{Conflict of interest}

The author declares no conflict of interest.

\section{References}

1. Klahr S, Morrissey J. Obstructive nephropathy and renal fibrosis. Am J Physiol Renal Physiol. 2002;283(5):F861-F875.

2. Dobyan DC, Levi J, Jacobs C, et al. Mechanism of cis-platinum nephrotoxicity: II. Morphologic observations. J Pharmacol Exp Ther. 1980;213(3):551-556.

3. Chopra S, Kaufman JS, Jones TW, et al. Cis diamminedichloroplatinum-induced acute renal failure in the rat. Kidney Int. 1982;21(1):5464.

4. Guinee DG, Van Zee B, Houghton DC. Clinically silent progressive renal tubulointerstitial disease during cisplatin chemotherapy. Cancer. 1993;71(12):4050-4054.

5. Dobyan DC. Long-term consequences of cis-platinum-induced renal injury: a structural and functional study. Anat Rec. 1985;212(3):239245.

6. Nangaku M. Mechanisms of tubulointerstitial injury in the kidney final common pathways to end-stage renal failure. Intern Med. 2004;43(1):9-17.

7. Matsunaga Y, Kawai Y, Kohda Y, et al. Involvement of activation of NADPH oxidase and extracellular signal-regulated kinase (ERK) in renal cell injury induced by zinc. J Toxicol Sci. 2005;30(2):135-144.

8. Nakatsuji S, Yamate J, Sakuma S. Macrophages, myofibroblasts, and extracellular matrix accumulation in interstitial fibrosis of chronic progressive nephropathy in aged rats. Vet Pathol. 1998;35(5):352-360.

9. Hewitson TD. Renal tubulointerstitial fibrosis: common but never simple. Am J Physiol Renal Physiol. 2009;296(6):F1239-F1244.

10. Sato S, Yamate J, Saito T, et al. Protective effect of taurine against renal interstitial fibrosis of rats induced by cisplatin. Naunyn Schmiedebergs Arch Pharmacol. 2002;365(4):277-283.

11. Sato S, Hori Y, Yamate J, et al. Protective effect of dietary azuki bean (Vigna angularis) seed coats against renal interstitial fibrosis of rats induced by cisplatin. Nutrition. 2005;21(4):504-511.

12. Sugihara K, Nakano S, Koda M, et al. Stimulatory effect of cisplatin on production of lipid peroxidation in renal tissues. Jpn J Pharmacol. 1987;43(3):247-252.

13. Solter D, Gearhart J. Putting stem cells to work. Science. 1999;283(5407):1468-1470.
14. Rosenbaum AJ, Grande DA, Dines JS. The use of mesenchymal stem cells in tissue engineering. Organogenesis. 2008;4(1):23-27.

15. Zahran F, El Ghareb M, Nabil A. Bone marrow derived mesenchymal stem cells as a therapy for renal injury. IJAR. 2014;4(4):11-16.

16. Kawai Y, Satoh T, Hibi D, et al. The effect of antioxidant on development of fibrosis by cisplatin in rats. J Pharmacol Sci. 2009;111(4):433-439.

17. Yamagishi H, Yokoo T, Imasawa T, et al. Genetically modified bone marrow-derived vehicle cells site specifically deliver an anti-inflammatory cytokine to inflamed interstitium of obstructive nephropathy. $J \mathrm{Im}$ munol. 2001;166(1):609-616.

18. Zhang W, Liao SS, Cui FZ. Hierarchical self-assembly of nano-fibrils in mineralized collagen. Mater. 2003;15(16):3221-3226.

19. Kivirikko KI, Prockop DJ. Hydroxylation of proline in synthetic polypeptides with purified protocollagen hydroxylase. $J$ Biol Chem. 1967;242(18):4007-4012.

20. Ohkawa H, Ohishi N, Yagi K. Assay for lipid peroxides in animal tissues by thiobarbituric acid reaction. Anal Biochem. 1979;95(2):351-358.

21. Kinomura M, Kitamura S, Tanabe K, et al. Amelioration of cisplatin-induced acute renal injury by renal progenitor-like cells derived from the adult rat kidney. Cell Transplan. 2008;17(1-2):143-158.

22. Cohen IK, Diegelmann RF, Wise WS. Biomaterials and collagen synthesis. J Biomed Mater Res. 1976;10(6):965-970.

23. Yamate J, Tatsumi M, Nakatsuji S, et al. Immunohistochemical observations on the kinetics of macrophages and myofibroblasts in rat renal interstitial fibrosis induced by cis-diamminedichloroplatinum. J Comp Pathol. 1995;112(1):27-39.

24. Skalli O, Ropraz P, Trzeciak A, et al. A monoclonal antibody against alpha-smooth muscle actin: a new probe for smooth muscle differentiation. J Cell Biol. 1986;103(6 Pt 2):2787-2796.

25. Scholzen T, Gerdes J. The Ki-67 protein: from the known and the unknown. J Cell Physiol. 2000;182(3):311-322.

26. Silver SA, Cardinal H, Colwell K, et al. Acute kidney injury: preclinical innovations, challenges, and opportunities for translation. Can J Kidney Health Dis. 2015;2:30.

27. Saad AA, Youssef MI, Shennawy LK. Cisplatin induced damage in kidney genomic DNA and nephrotoxicity in male rats:the protective effect of grape seed proanthocyanidin extract. Food Chem Toxicol. 2009;47(7):1499-1506.

28. Basnakian AG, Apostolov EO, Yin X, et al. Cisplatin nephrotoxicity is mediated by deoxyribonuclease I. J Am Soc Nephrol. 2005;16(3):697702.

29. Ali BH, Al Moundhri MS. Agents ameliorating or augmenting the nephrotoxicity of cisplatin and other platinum compounds: a review of some recent research. Food Chem Toxicol. 2006;44(8):1173-1183.

30. Kim M, Park YJ, Kim OJ, et al. Gene expression profiles related with overcoming cisplatin resistance in human cancer cell lines. Cancer Ther. 2003;1:21-29.

31. Boulikas T, Vougiouka M. Cisplatin and platinum drugs at the molecular level (review). Oncol Rep. 2003;10(6):1663-1682.

32. Satoh M, Kashihara N, Fujimoto S, et al. A novel free radical scavenger, edarabone, protects against cisplatin-induced acute renal damage in vitro and in vivo. J Pharmacol Exp Ther. 2003;305(3):1183-1190.

33. Qi S, Wu D. Bone marrow-derived mesenchymal stem cells protect against cisplatin-induced acute kidney injury in rats by inhibiting cell apoptosis. Int J Mol Med. 2013;32(6):1262-1272. 
34. Yao X, Panichpisal K, Kurtzman N, et al. Cisplatin nephrotoxicity: a review. Am J Med Sci. 2007;334(2):115-124.

35. Ghaly EN, Gergis SW, Aziz JN, et al. Role of mesenchymal stem cell therapy in cisplatin induced nephrotoxicity in adult albino rats: ultrastructural \& biochemical study. Acta Medica. 2014;1(2):57.

36. Kavita S, William S. Tubulointerstitial injury and the progression of chronic kidney disease. Pediatr Nephrol. 2012;27(6):901-909.

37. Ognjanović BI, Djordjević NZ, Matić MM, et al. Lipid peroxidative damage on Cisplatin exposure and alterations in antioxidant defense system in rat kidneys:a possible protective effect of selenium. Int $\mathrm{J} \mathrm{Mol}$ Sci. 2012;13(2):1790-1803.
38. Ohnishi S, Sumiyoshi H, Kitamura S, et al. Mesenchymal stem cells attenuate cardiac fibroblast proliferation and collagen synthesis through paracrine actions. FEBS Lett. 2007;581(21):3961-3966.

39. Sheashaa H, Lotfy A, Elhusseini F, et al. Protective effect of adipose-derived mesenchymal stem cells against acute kidney injury induced by ischemia-reperfusion in Sprague-Dawley rats. Exp Ther Med. 2016;11(5):1573-1580. 